\title{
LETTERS
}

\section{Diagnostic coding of routinely collected data}

I am writing with regard to the commentary by Nicholls and colleagues, ${ }^{1}$ and the linked study by Tang and colleagues. ${ }^{2}$

Both papers make important observations about the secondary-use value of routinely gathered clinical-administrative data for clinical, epidemiologic and health services research and reporting. They also point to some of the data quality challenges along the trajectory of collecting these data. The authors identify issues completeness and precision of physician documentation, inaccuracies in documentation, coder difficulty in understanding documentation, and so on - similar to some that the Canadian Institute for Health Information (CIHI) has identified through its own data quality analyses. Notwithstanding the challenges with respect to data quality, CIHI's most recent analysis found that the quality of abstract coding in the Discharge Abstract Database is very high, and that the data are fit for purpose for a wide variety of secondary uses. $^{3}$

Optimizing the quality of clinicaladministrative data is a leading priority for $\mathrm{CIHI}$ and is the foundation of its recently revised and updated Information Quality Framework, available at www.cihi.ca.
The authors of both the paper on coder perspectives and the commentary make several references to the International Statistical Classification of Diseases and Related Health Problems, 10th revision (ICD-10).

It may be useful to clarify for readers that two versions of ICD-10 are used in Canada. Statistics Canada uses the World Health Organization (WHO)-maintained ICD-10 to report on mortality statistics. ICD-10-CA, on the other hand, is a Canadian clinical modification of ICD-10, developed, maintained and supported by $\mathrm{CIHI}$ specifically for reporting morbidity statistics. It is the latter that is referred to in both papers, although without explicit acknowledgement.

As an example of the slow adoption of new diagnoses within the ICD-10 system, Nicholls and colleagues draw readers' attention to a particular ICD-10 code for eosinophilic esophagitis (K20.0). ${ }^{1}$ They observe that the code was adopted in 2015, "but is still not in use by most agencies that collect data." ${ }^{1}$ The United States, like Canada (and several other countries), has developed its own clinical modification of ICD-10. The K20.0 code is included in the US clinical modification of ICD-10, but it is not included in either of the variants of the classification in use in Canada.

ICD-10-CA is updated and revised regularly. Specific requests for enhancements can be submitted using the public submission request form available at www.cihi.ca. To date, there have been no requests for the inclusion of a specific code for eosinophilic esophagitis in ICD-10-CA. It will, however, be addressed in detail in ICD-11, which the WHO is currently completing.

$\mathrm{CIHI}$ is committed to collaborating to strengthen coding practices that will lead to better-quality data, and it welcomes feedback that will support this work.

\section{Keith Denny PhD}

Director, Clinical Data Standards and Quality, Canadian Institute for Health Information, Ottawa, Ont.

Cite as: CMAJ 2017 November 27;189: E1465. doi: 10.1503/cmaj.733419

\section{References}

1. Nicholls SG, Langan SM, Benchimol El. Routinely collected data: the importance of high-quality diagnostic coding to research. CMAJ 2017;189:E1054-5.

2. Tang KL, Lucyk K, Quan H. Coder perspectives on physician-related barriers to producing highquality administrative data: a qualitative study. CMAJ Open 2017;5:E617-22.

3. Data quality study of the 2015-2016 discharge abstract database: a focus on hospital harm. Ottawa: Canadian Institute for Health Information (CIHI); 2016. Available: https://secure.cihi.ca/ free_products/DAD_15_16_Reab_Report_EN.pdf (accessed 2017 Aug. 25).

Competing interests: None declared. 